\title{
Cursos de licenciatura nos Institutos Federais de Educação, Ciência e Tecnologia: considerações sobre um novo locus de formação de professores
}

\author{
BA Programs in Education at Brazil's Federal Institutes of Education, Science \\ and Technology: thoughts on a new locus of teacher education \\ Cursos de profesorado en los Institutos Federales de Educación, Ciencia y \\ Tecnología: consideraciones sobre un nuevo locus de formación de profesores
}

MARIA FLÁVIA BATISTA LIMA GLADYS BEATRIZ BARREYRO

\begin{abstract}
Resumo: O presente artigo discute a política de expansão das licenciaturas nos Institutos Federais de Educação, Ciência e Tecnologia (IFs) e problematiza a formação de professores nesse espaço, já que, historicamente, as instituições federais profissionais vinham ofertando cursos técnicos de nível médio. $\mathrm{O}$ texto é decorrente de pesquisa que analisou dados estatísticos, legislação, documentos governamentais e entrevistas. Finalmente, são apresentados alguns aspectos sobre o modelo de formação docente no IF, que evidencia a prevalência dos conhecimentos específicos disciplinares no currículo dos cursos e menor foco nas discussões das questões pedagógicas.
\end{abstract}

Palavras-chave: Formação de Professores; licenciaturas; Institutos Federais.

\begin{abstract}
The present article discusses the expansion policy of BA programs on education at Brazil's Federal Institutes of Education, Science and Technology (ISs), and problematizes teacher education in this context, since these federal vocational institutions have traditionally offered secondary-level vocational education. The text derives from a study that analyzed statistic data, legislation, government documents and interviews. Finally, we present a few aspects of the teacher education model at the FI, which shows the prevalence of specific content knowledge in curriculums and less focus on discussing pedagogical themes.
\end{abstract}

Keywords: teaching training; BA in education; Federal Institutes.

Resumen: Este artículo discute la política de expansión de los cursos de profesorado en los Institutos Federales de Educación, Ciencia y Tecnología (IFs) y problematiza la formación de profesores en ese lugar, ya que históricamente estas instituciones federales ofrecieron cursos técnicos profesionales. El texto es resultado de investigación que analizó datos estadísticos, legislación, documentos 
gubernamentales y entrevistas. Finalmente, se presentan algunos aspectos sobre el modelo de formación docente en el IF, que señala la prevalencia de los conocimientos específicos disciplinarios en el currículo de los cursos y menor foco en las discusiones de las cuestiones pedagógicas.

Palabras clave: Formación de profesores; cursos de profesorado; Institutos Federales.

\section{INTRODUÇÃO}

O texto discute o processo de expansão das licenciaturas nos Institutos Federais de Educação, Ciência e Tecnologia (IFs), no contexto da educação profissional e no marco da política governamental de criação dos IFs.

Os Institutos Federais foram constituídos, no fim do ano de 2008, com o intuito de reorganizar as instituições federais profissionais com a aglutinação de diversas instituições técnicas federais: Escolas Agrotécnicas Federais (EAFs), Escolas Técnicas Federais (ETFs), Centros Federais de Educação Tecnológica (CEFETs) e Escolas Técnicas Vinculadas às Universidades Federais (EVs) (BRASIL, 2008).

Historicamente, as instituições federais profissionais atuaram, preponderantemente, no oferecimento de cursos técnicos de nível médio. Todavia, já no início dos anos 2000, alguns pesquisadores apontavam a tendência de expansão da educação superior nessas instituições (CIAVATTA, 2006; FRIGOTTOO; CIAVAT'TA; RAMOS, 2005).

A pesquisa que originou esta análise constatou a ampliação dos cursos de graduação nos Institutos Federais, desde bacharelados, cursos tecnológicos e, especialmente, dos percentuais de matrículas em licenciaturas, sobretudo a partir do ano de 2010. Diante dessa realidade, verificou-se a importância de se investigar a expansão e as características das licenciaturas nos IFs, pois as instituições profissionais não tinham tradição na oferta desse tipo de curso. Considerou-se, ainda, a possibilidade de contribuir com análises do novo formato institucional.

No texto também são problematizados alguns aspectos sobre o processo de criação das licenciaturas, revelando alguns dados sobre os percursos e as concepções que envolveram o estabelecimento dos cursos destinados à formação de professores nesse cenário. Os dados qualitativos da pesquisa e documentos institucionais foram coletados no Instituto Federal de São Paulo (campus São Paulo), no período de 2014-2015, apesar de a expansão de licenciaturas ter ocorrido, nesse período, no conjunto dos Institutos Federais. Contudo, não é possível generalizar os resultados dessa pesquisa para a totalidade dessa rede 
federal, pois os processos institucionais são diferentes e as instituições que originaram os IFs também possuíam características peculiares, desde diferenças regionais até, mesmo, especificidades em seus modelos institucionais precedentes.

\section{CURSOS DE FORMAÇÃO DE PROFESSORES NO BRASIL: ALGUMAS CONSIDERAÇÕES}

As primeiras iniciativas de formação de professores no Brasil surgiram no século XIX, com a criação das primeiras Escolas Normais destinadas à formação de docentes para as escolas primárias. O currículo da Escola Normal abrangia os seguintes conhecimentos: quatro operações matemáticas e proporções; leitura e escrita; fundamentos de geografia e princípios da moral cristã (TANURI, 2000).

Segundo a autora, a formação de professores no século XIX enfrentou muitos problemas, tais como: o pouco interesse pela profissão de professor, devido, entre outras coisas, à baixa remuneração; a carência de entendimento de que uma formação específica aos docentes fosse necessária e algumas falhas didáticas no próprio processo formativo.

Muitas províncias escolhiam os professores a partir de exames, os quais se restringiam a aferir o conhecimento dos pretendentes em relação aos conteúdos do ensino primário, condição que conduziu ao magistério docentes com baixa qualificação.

O modelo das Escolas Normais começou a difundir-se com a reforma da instrução pública do estado de São Paulo, no ano de 1890, e um modelo de organização foi estabelecido com a introdução de mudanças nos conteúdos curriculares e nas práticas de ensino (SAVIANI, 2009). Para o autor, a reforma paulista desempenhou papel importante para o desenvolvimento das Escolas Normais também em outros estados brasileiros. Todavia, "após a primeira década republicana o ímpeto reformador se arrefeceu” (SAVIANI, 2009, p. 145) e novas experiências na área da educação foram efetivadas com a criação de Institutos de Educação.

Segundo o autor, esses Institutos foram idealizados para o desenvolvimento da educação, do ensino e da pesquisa. As principais experiências foram: o Instituto de Educação do Distrito Federal, criado por Anísio Teixeira, em 1932, e o Instituto de Educação de São Paulo, organizado por Fernando de Azevedo, em 1933.

Os Institutos de Educação citados foram incorporados às universidades criadas na década de 1930. Em 1935, o Instituto do Distrito Federal foi integrado à Universidade do Distrito Federal e, em 1934, o Instituto de São Paulo, à Universidade de São Paulo (SAVIANI, 2005). De acordo com o autor, 
dessas experiências surgiu um novo modelo de formação de professores para a atuação no ensino secundário e nas Escolas Normais, com o estabelecimento, respectivamente, dos cursos de Licenciatura e de Pedagogia.

Até a década de 1930, havia pouquíssimas escolas secundárias no país e eram profissionais liberais quem exercia a docência nessas instituições (GATTI, 2010). De acordo com a autora, a preocupação com a formação de professores para este nível surgiu no início do século XX; contudo, os cursos de formação só foram iniciados com a criação das universidades.

O modelo de licenciaturas, nas primeiras universidades, estabeleceu-se a partir dos cursos de bacharelado com o incremento de disciplinas da área de educação em mais um ano, padrão de formação que ficou conhecido como $3+1$.

Para Diniz-Pereira (1999), a formação idealizada com o modelo 3+1 tem inspiração no modelo da racionalidade técnica, no qual "o professor é visto como um técnico, um especialista que aplica com rigor, na sua prática cotidiana, as regras que derivam do conhecimento científico e do conhecimento pedagógico" (p. 111-112).

Para o autor, a formação de professores baseada no modelo da racionalidade técnica mostra-se ineficiente ao trabalho desenvolvido na escola, devido ao foco na formação teórica e também por seu distanciamento da prática educativa.

Segundo Gatti (2014), historicamente, os cursos de licenciatura separaram os conhecimentos específicos dos conhecimentos pedagógicos no processo formativo e também destinaram parte menor do currículo às atividades práticas. Essa separação de conhecimentos nos currículos e o predomínio de alguns saberes não vêm favorecendo um modelo formativo com foco na docência.

A questão da prática na formação docente configura também outro impasse para a melhoria dos cursos de licenciatura. Para Gatti, Barreto e André (2011), a articulação entre teoria e prática é pouco explicitada nos currículos das licenciaturas no Brasil até a atualidade. Nesses cursos, ainda prevalece uma “formação acadêmica, mais abstrata, de caráter excessivamente genérico" (p. 91).

Portanto, ao longo do tempo, poucas mudanças ocorreram nas licenciaturas, que conservam elementos de sua gênese. As pesquisas educacionais indicam que o modelo formativo pouco avançou devido também às políticas descontínuas para a área educacional no país. Dessa forma, ainda não se estabeleceu um padrão de curso de formação consistente e compatível com as demandas da Educação Básica brasileira. 


\section{INSTITUTOS FEDERAIS: NOVO LOCUS DE FORMAÇÃO?}

Os primeiros cursos de licenciatura foram iniciados nas universidades, na década de 1930, como já destacado. Segundo Teixeira (1966), o próprio modelo de Faculdade de Filosofia, Ciências e Letras foi criado nesse período com o intuito de enfrentar os desafios da ampliação dos sistemas escolares, contribuindo para a formação de professores, especialistas e pesquisadores, assim como para propagar a cultura geral. Tradicionalmente, a universidade tem sido considerada o local privilegiado para a formação docente.

Nessa conjuntura, as licenciaturas e o curso de Pedagogia se estabeleceram como os cursos para a formação, respectivamente, de docentes para o ensino secundário e para a Escola Normal ${ }^{1}$, que formava por sua vez os professores para o nível primário ${ }^{2}$. Assim, esses cursos tiveram sua gênese com a universidade como o locus para o seu desenvolvimento.

Segundo Dourado (2001), a universidade pode realizar uma formação de qualidade pela possibilidade de atuar por meio da indissociabilidade entre ensino, pesquisa e extensão e ainda por sua articulação com a sociedade civil.

Diniz-Pereira (2010) também discute o papel da instituição universitária na formação docente e destaca que a vivência com os procedimentos e os resultados das pesquisas científicas pode favorecer habilidades nos alunos e futuros professores, tais como: a análise crítica da atuação docente; a fundamentação teórica para as ações educativas e um entendimento aprofundado dos processos pedagógicos na escola.

$\mathrm{O}$ autor destaca ainda que as universidades são as instituições com o maior potencial para dar soluções aos problemas nacionais, incluindo as demandas educacionais. Nesse sentido, compete especialmente às universidades públicas o "desafio e o compromisso social de formar, de maneira diferenciada, profissionais da educação capazes de atuar como agentes de mudança na escola básica, no Brasil" (DINIZ-PEREIRA, 2010, p. 537).

A Associação Nacional pela Formação dos Profissionais da Educação (Anfope), historicamente, apresentou entre seus princípios a defesa da universidade como o locus principal para a formação dos profissionais da educação (ANFOPE,

\footnotetext{
1 O modelo da Escola Normal permaneceu até a década de 1970, quando foi substituída pela Habilitação Específica de Magistério que seguiu até 1996 (SAVIANI, 2009). A Lei de Diretrizes e Bases $n^{\circ}$ 9394/1996, estabeleceu a formação de professores em nível superior (licenciaturas para todas as etapas da Educação Básica) e, a partir de então, os cursos nessa modalidade entraram em vacância (BRASIL, 1996).

2 Após a Constituição Federal de 1988, o ensino secundário passou a denominar-se Ensino Médio e o ensino primário passou a ser chamado Ensino Fundamental (BRASIL, 1988).
} 
2010). Essa defesa esteve apoiada, principalmente, pela possibilidade da pesquisa universitária como princípio formativo e de suas contribuições para a articulação entre teoria e prática.

Mesmo com muitas indicações pertinentes à oferta dos cursos de formação de professores nas universidades, é importante assinalar algumas críticas e observações levantadas sobre esses cursos nesse modelo institucional. Para Teixeira (1966), em seu desenvolvimento, a universidade distanciou-se dos problemas do magistério do ensino primário e secundário e "limitou-as à formação, quando muito, dos especialistas nas disciplinas literárias e científicas, tendo mais em vista o ensino superior do que o ensino nas escolas" (p. 7).

Nesse sentido, o próprio Anísio Teixeira já indicava a necessidade de mudanças nos currículos dos cursos de licenciatura ofertados nas instituições universitárias, especialmente para responder às especificidades da docência. Menezes (1986) fez crítica semelhante, indicando a necessidade de revisão dos cursos de licenciatura com foco nos conhecimentos específicos e semelhantes aos bacharelados, para um formato que privilegiasse os conhecimentos práticos e os pedagógicos, segundo as demandas da escola básica.

Gatti, Barreto e André (2011) fazem críticas à formação de professores no Brasil, que continua sendo realizada em cursos separados "com base na "divisão da ciência; cursos sem articulação entre si, sem uma base compartilhada e com clara separação interna entre formação em área disciplinar e formação pedagógica" (p. 95).

Especificamente a oferta de licenciaturas nos Institutos Federais (IFs) foi anunciada no Plano de Desenvolvimento da Educação (PDE ${ }^{3}$ ), em abril de 2007, antes mesmo da criação dos IFs, (BRASIL, 2007). Segundo esse plano, seria criada uma nova instituição com o nome de Instituto Federal de Educação, Ciência e Tecnologia (IF), com a atribuição de ofertar formação de professores, sobretudo nas áreas de Química, Física, Biologia e Matemática, entre outras funções.

O documento Concepção e Diretrizes: Instituto Federal de Educação, Ciência e Tecnologia, da Secretaria de Educação Profissional e Tecnológica (SETEC), reafirma esse foco dos IFs nos programas de formação de professores, ou licenciaturas, nas mesmas áreas destacadas pelo Plano de Desenvolvimento da Educação (PDE), devido à falta de professores para a educação básica (BRASIL, 2008a).

3 O Plano de Desenvolvimento da Educação (PDE) foi apresentado no início do segundo governo de Luiz Inácio Lula da Silva, em 2007. Segundo Saviani (2007), o PDE apresentou 30 ações direcionadas à educação em seus vários níveis e modalidades, com foco na qualidade do ensino. No entanto, o autor faz críticas à proposta por não apresentar garantias à sua realização. 
A proposta inicial de expansão das licenciaturas nos IFs estimava 100 mil matrículas nesses cursos quando as instituições estivessem em amplo funcionamento (BRASIL, 2008a). A análise dos dados do Censo da Educação Superior 2015 do INEP apontaram 39.662 matrículas em licenciaturas nos IFs (BRASIL, 2017).

Segundo os documentos governamentais, o contexto da carência de professores no país foi uma das principais justificativas para a expansão das licenciaturas nos Institutos Federais. Entre outros argumentos, destacou-se o potencial de formação das instituições da rede federal profissional, especialmente de sua estrutura e dos seus profissionais qualificados, sobretudo, nas áreas de Ciências e Matemática.

A Lei $\mathrm{n}^{\circ}$ 11.892/2008 apontou que os Institutos Federais devem destinar vinte por cento de suas vagas a cursos de licenciatura e em programas de formação pedagógica (BRASIL, 2008). O Decreto n ${ }^{\circ} 6.095 / 2007^{4}$, anterior a Lei n 11.892/2008, já indicava que os Institutos Federais deveriam aplicar o "mínimo de vinte por cento de sua dotação orçamentária anual” (BRASIL, 2007a, Art. $\left.5^{\circ}\right)$ no desenvolvimento de cursos destinados à formação de professores. A Lei, porém, assegurou vinte por cento das vagas dos IFs nesses cursos.

O processo de criação de leis, no Brasil, geralmente compreende alterações na composição do texto, devido às disputas e aos interesses políticos. Verificou-se que o Decreto $n^{\circ}$ 6.095/2007 garantia um percentual de recursos para a oferta de licenciaturas, enquanto a Lei $n^{\circ} 11.892 / 2008$ inclúa apenas a obrigatoriedade de oferta dos cursos, sem a indicação de recursos para esta finalidade.

A importância das licenciaturas nos Institutos Federais é citada nos documentos governamentais, inclusive, como um dos aspectos do próprio processo de consolidação dos recentes IFs, pois questões pedagógicas e formativas desses cursos podem contribuir para outras áreas e cursos das instituições.

No Gráfico 1, é possível verificar a evolução das matrículas em licenciaturas nos Institutos Federais.

4

O Decreto $n^{\circ}$ 6.095/2007 estabeleceu as diretrizes para o processo de integração das instituições federais profissionais. 


\section{Gráfico 1 - Evolução das matrículas nas licenciaturas, modalidade presencial, nos Institutos Federais - (2008-2015).}

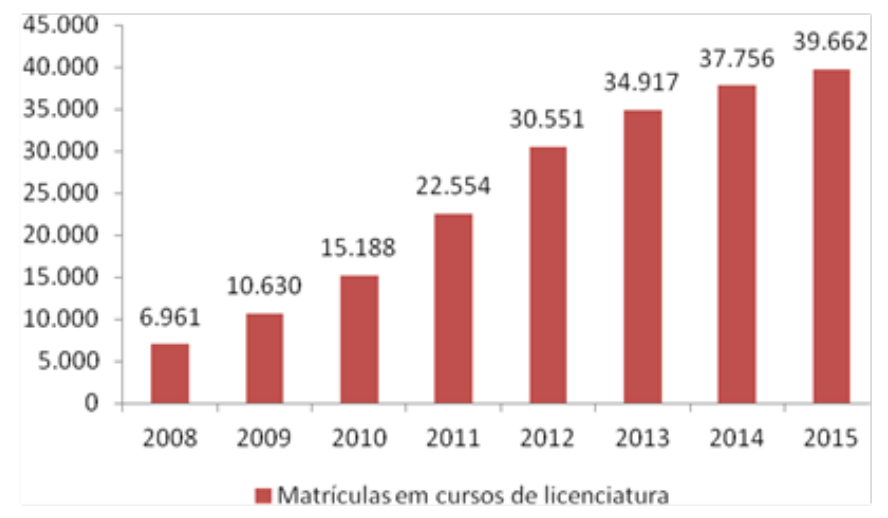

Fonte: BRASIL/INEP (2017). Elaboração própria.

A proposta das licenciaturas dos Institutos Federais é ainda debatida de forma breve em alguns documentos da Secretaria de Educação Profissional e Tecnológica (Setec). O documento Concepção e Diretrizes: Instituto Federal de Educação, Ciência e Tecnologia destaca uma possibilidade de percurso formativo para os cursos de licenciatura:

A vinculação estreita entre as ciências e a tecnologia, em diversas áreas, é capaz de gerar uma concepção da formação que se configure num programa ou ciclo inicial, tendo como base cada uma das áreas das ciências, configuração que pode trazer caráter de terminalidade, como bacharelado. A partir de então, seria possível encaminhar o educando para licenciaturas (Biologia, Física, Matemática, Química e afins) [...] (BRASIL, 2008a, p. 31).

O caráter de terminalidade do bacharelado parece resgatar o modelo histórico de licenciatura, antes descrito. $\mathrm{O}$ documento Contribuições para o processo de construção dos cursos de licenciatura dos Institutos Federais sugere um currículo com uma proposta que aprofunda ideias em uma perspectiva mais integrada, porém com saberes divididos em núcleos. 
A base curricular comum - Núcleo Comum - é composta pelo Núcleo Básico (de saberes comuns à área de conhecimento e "instrumentais" inerentes à formação de profissionais da educação) e pelo Núcleo Pedagógico, desenvolvidos numa perspectiva integradora, trabalhados, preferencialmente, ao longo de toda a formação. Os conhecimentos relacionados à formação específica docente, seja na perspectiva do aprofundamento dos conhecimentos científico-tecnológicos relativos à habilitação escolhida, seja na perspectiva da transposição didática dos conteúdos, são ministrados no Núcleo Específico (BRASIL, 2009, p. 5; grifo no original).

Freitas (2007) assinala que os Institutos Federais atuariam também na oferta de licenciaturas e em programas de formação pedagógica, inclusive, para habilitar professores para a atuação na própria educação profissional tecnológica. Tal proposta, para a autora, seria polêmica e precisaria de maior debate.

É interessante observar que a ampliação da formação de professores na rede federal profissional é proposta, justamente, com o estabelecimento de uma nova instituição e nomeada por instituto. Ortigara (2012) discute o processo de criação dos IFs e enfatiza que a designação de instituto não foi algo novo na legislação, pois já estava presente na LDB n 9.394/96 como outra possibilidade de locus de formação docente. Todavia, o autor assinala que os IFs possuem outras finalidades, além da formação de professores, tais como a oferta de Educação Básica, Educação Profissional em todos os níveis, cursos superiores e pósgraduação.

Otranto (2012) discute as muitas atribuições dos Institutos Federais e ressalta que eles ainda atuam como instituições acreditadoras e certificadoras de competências profissionais. A autora apresenta inquietações sobre o oferecimento das licenciaturas nesse contexto e aponta que a atuação nessa área demanda recursos específicos, tais como bibliotecas, laboratórios e professores qualificados.

É importante destacar, ainda, a expressiva expansão de campi dos Institutos Federais, principalmente em cidades do interior do Brasil, o que também pode ser um elemento estratégico para um plano de ampliação da formação docente em instituições públicas. No fim de 2014, os IFs contavam com 499 campi distribuídos pelo país (OTRANTO, 2015).

Enfim, a literatura indica que a universidade é o local privilegiado da formação de professores, principalmente pela possibilidade de articular ensino, pesquisa e extensão. Todavia, é imperativa uma mudança no modelo dos cursos de licenciatura ofertados nas próprias universidades. Esses aspectos foram discutidos como referencial para aprofundar o debate sobre o significado da ampliação do locus de formação de professores nos Institutos Federais e para a sequência das análises. 


\section{O PROCESSO DE CONSTRUÇÃO DAS LICENCIATURAS NO INSTITUTO FEDERAL DE SÃO PAULO (IFSP)}

O Instituto Federal de São Paulo (IFSP) foi criado com a Lei $\mathrm{n}^{\circ}$ 11.892/2008, que transformou o Centro Federal de Educação Tecnológica de São Paulo (CEFET-SP) em Instituto Federal (BRASIL, 2008).

Os primeiros cursos de licenciatura foram criados no campus São Paulo, ainda no CEFET-SP. A licenciatura em Física foi o primeiro curso, iniciado no ano de 2001. A segunda licenciatura só começou em 2007, com o curso de Geografia. Em 2008, foram criadas duas novas licenciaturas: Matemática e Ciências da Natureza, sendo que esse último curso foi extinto após um ano, dando origem aos novos cursos de licenciatura em Biologia e em Química. Os alunos que cursavam licenciatura em Ciências da Natureza optaram por continuar em um desses cursos de Química ou de Biologia, conforme seus interesses. Em 2012 teve início a licenciatura em Letras (IFSP, 2014).

As licenciaturas do campus São Paulo do IFSP foram criadas, assim, entre os anos de 2001 e 2012. A análise dos microdados do Censo da Educação Superior do INEP (2001-2015) indicou que a expansão do número de matrículas em cursos de licenciatura aconteceu, principalmente a partir de 2008, após a transformação do CEFET-SP em IFSP.

As entrevistas realizadas com técnico-administrativos e professores do IFSP revelaram algumas motivações para a abertura das licenciaturas, primeiro pela demanda de professores para as áreas de Ciências e Matemáticas nas redes públicas de ensino e também pela carência de vagas em cursos de formação nessas áreas em instituições públicas na cidade de São Paulo.

O próprio Plano de Desenvolvimento Institucional IFSP 2009-2013 indicou que a oferta das licenciaturas se justifica pela demanda de professores e ressaltou a importância de "formar professores para a educação básica, principalmente para o ensino de Física, Matemática, Química e Biologia e, por outro, requalificar os docentes que estão em atividade" (IFSP, 2009, p. 39).

Nos depoimentos das entrevistas, destacou-se a ideia de que as licenciaturas teriam menor expressividade nas universidades públicas e privadas, principalmente na área de exatas, devido à maior valorização dos bacharelados nas universidades públicas e ao pouco investimento em laboratórios e recursos, no caso das universidades privadas.

Os dados apontaram também que a criação das licenciaturas emergiu de discussões dos docentes em suas áreas de lotação, pois a existência de um curso poderia consolidar a área de conhecimento na instituição, o que aumentaria a 
participação dessas áreas nos espaços de gestão. O grande número de professores com mestrado e doutorado favoreceu, também, a abertura das licenciaturas, assim como o prestígio para os docentes, ao atuarem em cursos de nível superior.

A análise dos documentos institucionais e dos depoimentos dos profissionais do IFSP mostrou, ainda, que as primeiras propostas de cursos superiores na instituição possuem relação com o fim do ensino médio técnico integrado, no final da década de 1990. Nesse contexto, é importante lembrar que, por meio do Decreto n ${ }^{\circ}$ 2.208/1997, a educação profissional de nível técnico passou a ser oferecida apenas nas modalidades concomitante ou subsequente, extinguindo a oferta de ensino médio integrado ao nível técnico em um único curso (BRASIL, 1997). Por um lado, essa reforma foi reduzindo o número de turmas no Ensino Médio e, por outro lado, estimulou a criação dos cursos apenas técnicos e dos cursos de nível superior durante os anos 2000.

Nessa conjuntura, alguns professores das áreas técnicas propuseram a criação dos cursos superiores de tecnologia e os professores das áreas gerais ou, também das nomeadas propedêuticas, foram os responsáveis pelos primeiros projetos para a criação das licenciaturas.

Os depoimentos ressaltaram que, atualmente, há poucas discussões sobre a concepção das licenciaturas na instituição e isso ocorre, especialmente, porque há um grupo reduzido de professores e de pesquisadores da área de Educação. Dessa forma, destacam-se os conhecimentos específicos no desenvolvimento dos cursos.

Os argumentos que embasaram a criação das licenciaturas no IFSP foram: a escassez de licenciaturas oferecidas por instituições públicas, já que a maioria destes cursos é ofertada por instituições privadas; a alta demanda de professores para atuação nas áreas de Ciências e Matemática; a autorização e incentivo de legislações federais; a garantia de espaço e a possibilidade de ampliar a quantidade de aulas na instituição; a possibilidade de ocupação de cargos de gestão e o prestígio de exercer a docência em cursos de nível superior. Essas questões permitiram a abertura dos cursos com a infraestrutura que a instituição já tinha, desde o corpo docente, os laboratórios e a própria estrutura física, que foi sendo expandida paulatinamente.

\section{A FORMAÇÃO ACADÊMICA DOS PROFESSORES DAS LICENCIATURAS NO IFSP}

No desenvolvimento da pesquisa, constatou-se que os professores que atuavam nas licenciaturas tinham sua lotação em Coordenadorias e Áreas da Diretoria Acadêmica de Formação Geral; são elas: Coordenadoria de Ciência 
e Tecnologia (Áreas: Biologia, Física, Química e Matemática); Coordenadoria de Códigos e Linguagens (Áreas: Educação Física, Artes e Português/Inglês) e Coordenadoria de Sociedade e Cultura, sem áreas relacionadas.

Verificou-se que não havia uma área propriamente de Educação. Segundo relatos feitos nas entrevistas, havia poucos profissionais com formação nessa área. Esse fato impulsionou a ampliação da pesquisa no sentido de investigar a formação acadêmica dos professores que lecionavam nos cursos de licenciatura.

Os docentes que atuam nas licenciaturas também não estão lotados em um só curso, ou seja, podem atuar em mais de uma licenciatura concomitantemente, assim como dar aulas em outros cursos da instituição.

$\mathrm{Na}$ Tabela 1, é possível verificar as áreas e o número dos professores lotados da Diretoria Acadêmica de Formação Geral e que poderiam atuar nas licenciaturas.

\section{Tabela 1 - Número de professores da Diretoria Acadêmica de Formação Geral do campus São Paulo do IFSP, por área - (2014).}

\begin{tabular}{|c|c|c|}
\hline \multicolumn{2}{|c|}{ Diretoria Acadêmica de Formação Geral (DFG) } \\
\hline Coordenadoria & Área & $\mathrm{n}^{\circ}$ de professores \\
\hline \multirow{3}{*}{ Ciência e Tecnologia (CCT) } & Biologia & 15 \\
\cline { 2 - 3 } & Física & 21 \\
\cline { 2 - 3 } & Matemática & 33 \\
\cline { 2 - 3 } & Química & 16 \\
\hline \multirow{3}{*}{ Códigos e Linguagem (CCL) } & Educação Física & 5 \\
\cline { 2 - 3 } & Artes & 5 \\
\cline { 2 - 3 } & Português/lnglês & 27 \\
\hline Sociedade e Cultura (CSC) & - & 27 \\
\hline Total & & 149 \\
\hline
\end{tabular}

${ }^{5}$ Fonte: Lima (2015, p.131).

A atribuição das aulas dos docentes nas licenciaturas envolve critérios relacionados à sua titulação e ao seu tempo de serviço na instituição. A titulação dos docentes das licenciaturas mostra que $95 \%$ deles possuíam pós-graduação, sendo 3\% em nível de Especialização, 50\% em Mestrado e 42\% em Doutorado, conforme apresentado no Gráfico 2.

5 A Coordenadoria de Sociedade e Cultura (CSC) não possui áreas, nela estão lotados os professores de Filosofia, Sociologia, História e Geografia da instituição. 


\section{Gráfico 2 - Percentual e número absoluto dos professores da Diretoria Acadêmica de Formação Geral do campus São Paulo do IFSP, por nível de formação em pós-graduação - (2014).}

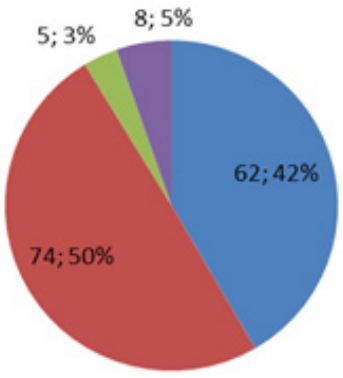

Eoutorado = Mestrado Especializaçăo = Graduaçåo

Fonte: Lima (2015, p. 135).

Nos depoimentos, constatou-se que a titulação dos docentes tem conotação muito positiva na instituição. Os dados indicam um percentual elevado de docentes com pós-graduação, sobretudo, nos níveis de mestrado e doutorado.

No Gráfico 3, são detalhadas as áreas de titulação dos docentes em nível de pós-graduação, em que se destacam 11 professores com formação na área de Educação, o que significa 7,4\% do total de docentes. Há também 12 professores com formação na área de Ensino de História, Filosofia das Ciências e Matemáticas e 8 na área de Educação Matemática, o que soma 20 docentes com formação nessas duas áreas afins à Educação. A formação dos professores dessas duas áreas perfaz 13,4\% do corpo docente. A formação dos outros 118 professores está concentrada em áreas específicas de conhecimento, o que representa 79,2\% do grupo de docentes.

Ainda sobre os dados do Gráfico 3, é interessante destacar que 8\% dos professores possuem formação em Engenharia e Profissionalizante em Matemática, áreas não comuns à docência ${ }^{6}$. A contratação de profissionais dessas áreas traduz também demandas de outros cursos realizados na instituição, uma vez que os professores da Diretoria Acadêmica de Formação Geral podem ministrar aulas em cursos técnicos, tecnológicos, bacharelados, entre outros ofertados na instituição.

No Gráfico 2, a variável outros refere-se à formação de um professor em cada das seguintes áreas e níveis: Educação Física, Literatura, Música e Oceanografia (Mestrado); Arquitetura e Urbanismo, Computação e Estatística (Doutorado) e a área não foi informada no nível de Especialização. 
Gráfico 3 - Formação dos professores da Diretoria Acadêmica de Formação Geral, por área do conhecimento, em nível de pós-graduação do campus São Paulo do IFSP - (2014).

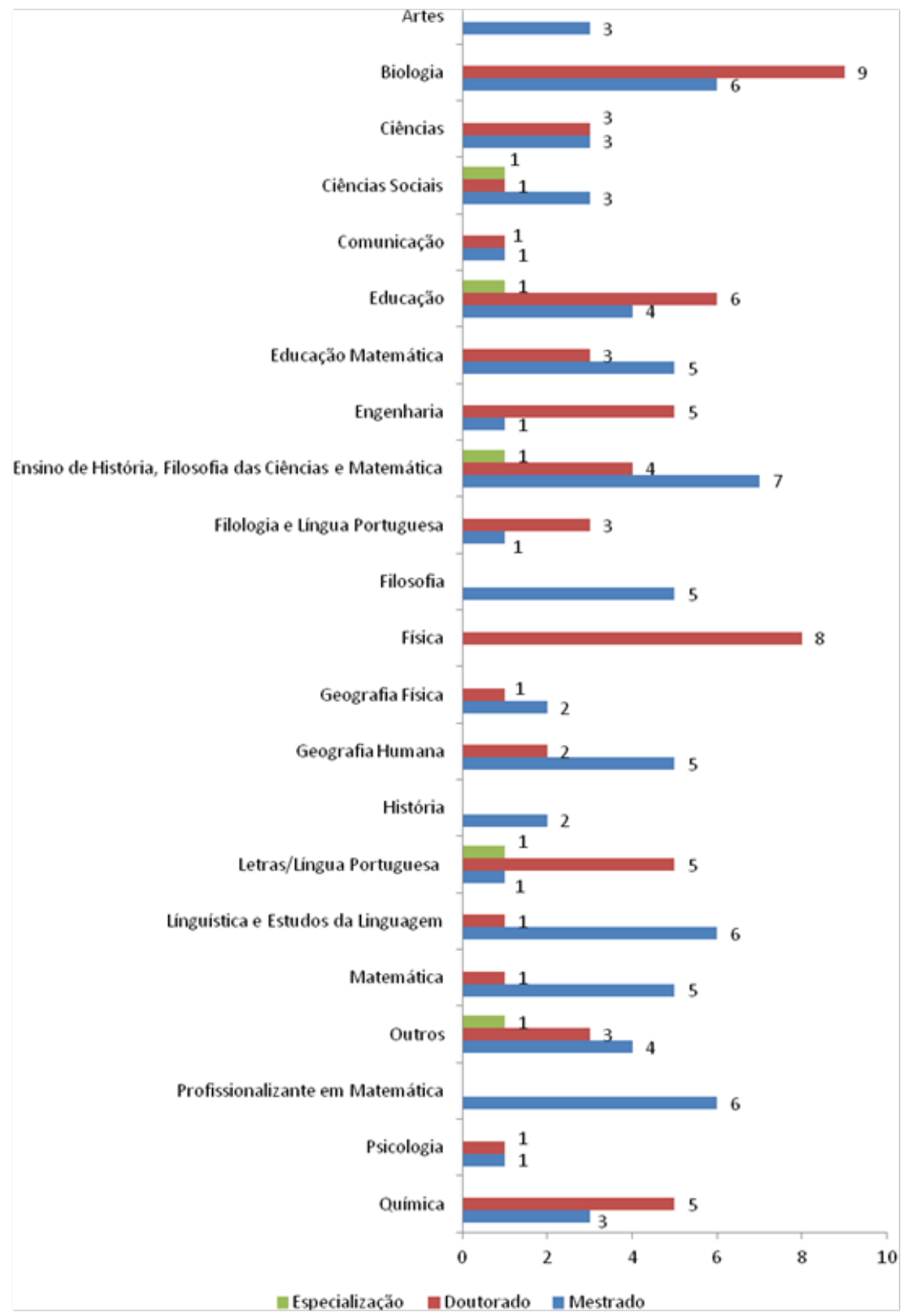

Fonte: Lima (2015, p. 136). 
A atuação do professor em diferentes cursos, ao mesmo tempo, é um grande desafio dos profissionais da instituição, uma vez que o trabalho docente "Envolve saberes específicos, os saberes pedagógicos e os saberes construídos nos espaços da experiência" (VEIGA, 2008, p. 20), o que implica, portanto, articulação de teoria e prática. Dessa forma, o exercício da docência em vários cursos demanda ainda mais tarefas aos docentes do IFSP, pois inclui reconhecer os propósitos distintos dos cursos e seus respectivos espaços de atuação, assim como as singularidades dos perfis profissionais.

Diniz-Pereira (2000) investiga as características do trabalho docente e destaca que essa atividade compreende conhecimentos e ações que excedem a tarefa de transmitir conhecimento. Para o autor, a função do professor envolve muitas dimensões, das quais destaca:

Entender as diferenças e semelhanças dos processos de produção do saber científico e do saber escolar, conhecer as características da cultura escolar, saber a história da ciência e a história do ensino da ciência com que trabalha e em que pontos elas se relacionam (DINIZ-PEREIRA, 2000, p. 47).

As pesquisas em educação explicitam que a formação de professores é uma questão importante a ser considerada para a construção de uma Educação Básica de qualidade; todavia é imperativo "reconhecer a especificidade da formação docente e garantir aos cursos de licenciatura um projeto pedagógico específico" (ARANHA; SOUZA, 2013, p. 81).

Os dados analisados, no entanto, indicam um modelo de licenciatura semelhante ao tradicionalmente estabelecido e discutido aqui. As informações sobre a formação em pós-graduação dos docentes das licenciaturas indicaram o predomínio da titulação em áreas específicas, o que ajudou a compreender algumas indicações dos entrevistados sobre o processo de construção dos cursos, tais como: o pouco debate propriamente sobre educação e a valorização dos conhecimentos específicos em relação aos conhecimentos pedagógicos.

Em geral, as licenciaturas apresentam muitos problemas no Brasil, pois também nesses cursos há "pouca penetração e consideração das orientações e resultados de discussões e pesquisas sobre formação de professores na institucionalização dos cursos formadores nas diferentes áreas disciplinares abrangidas" (GATTI, 2014, p. 36).

Nesse sentido, a construção de um curso de qualidade implica considerar os resultados das pesquisas na área da Educação e no próprio campo da formação docente. 
A estruturação de uma proposta de formação de professores compreende alguns pressupostos, tais como: uma compreensão aprofundada da própria área da Educação; a coerência das estratégias pedagógicas do curso com as finalidades formativas, ou seja, direcionadas à docência; uma fundamentação teórica baseada nos resultados das pesquisas educacionais e um compromisso com a construção de uma escola pública de qualidade para todos. Portanto, "não é possível pensar e construir uma proposta formativa sem ter por base uma clara concepção de formação e seus princípios fundantes" (VEIGA; VIANA, 2011, p. 19).

Finalmente, a constituição de um currículo para as licenciaturas coerente com o exercício da docência implica mudanças, como discutido, especialmente na perspectiva de superar a abordagem tradicional dos cursos e de seus limites para a construção de uma Educação Básica, democrática e de qualidade.

\section{CONSIDERAÇÕES FINAIS}

A oferta de licenciaturas foi iniciada antes mesmo da criação dos IFs, no caso do Instituto Federal de São Paulo (IFSP). Alguns cursos de licenciatura foram criados ainda no CEFET-SP. Verificou-se que os projetos dessas primeiras licenciaturas também se relacionam com a reforma da Educação Profissional, no final da década de 90 .

Nessa reforma, a oferta do Ensino Médio integrado à formação profissional foi proibida, situação que reduziu o número de aulas da nomeada formação geral na instituição. Nessa situação, a proposição de licenciaturas teve também a finalidade de evitar uma possível ociosidade dos docentes, que antes ministravam aulas principalmente nas disciplinas vinculadas à formação geral do anterior ensino médio integrado. Os dados mostraram, todavia, que não faltaram aulas para os docentes no período; ao contrário, a quantidade de aulas foi ampliada com a criação das licenciaturas e de outros cursos.

A análise dos dados indicou um percentual alto de docentes da instituição com mestrado e doutorado, o que não pode deixar de ser valorizado, pois também são profissionais concursados e, predominantemente, com dedicação exclusiva. Nessa conjuntura, a ampliação do quadro de docentes na área da Educação poderia contribuir com o desenvolvimento de discussões relacionadas às concepções políticas e pedagógicas das licenciaturas, assim como para fomentar o próprio tema da educação na instituição, considerando o momento importante de reconfiguração de sua identidade.

Finalmente, a continuidade de pesquisas sobre a expansão das licenciaturas nos Institutos Federais poderá mostrar seus significados, progressos e limites dada a necessidade de, desde o setor público, propiciar a formação docente. 


\section{REFERÊNCIAS}

ANFOPE - Associação Nacional pela Formação dos Profissionais da Educação. Documento final do $\mathbf{1 5}^{\circ}$ encontro nacional, 2010. Goiás, Caldas Novas, nov. 2010. Disponível em: <http://www.gppege.org.br/home/secao.asp?id_ secao $=186>$. Acesso em: 8 fev. 2015.

ARANHA, A. V. S.; SOUZA, J. V. A. de. As licenciaturas na atualidade: nova crise? Educar em Revista, Curitiba, Editora UFPR, n. 50, p. 69-86, out./dez. 2013.

BRASIL. Instituto Nacional de Estudos e Pesquisas Educacionais Anísio Teixeira (INEP). Microdados do Censo da Educação Superior 2001-2015. Brasília: INEP, jul. 2017. Disponível em: < http://portal.inep.gov.br/web/guest/ microdados >. Acesso em: jul. 2017.

- Ministério da Educação. Secretaria de Educação Profissional e Tecnológica (Setec). Contribuições para o processo de construção dos cursos de licenciatura dos Institutos Federais de Educação, Ciência e Tecnologia. 2009. Disponível em: <http://portal.mec.gov.br/index.php?option=com_conte nt\&view $=$ article\&id $=12503 \&$ Itemid $=841>$. Acesso em: out. 2012.

. Lei no 11.892, de 29 de dezembro de 2008. Institui a Rede Federal de Educação Profissional, Científica e Tecnológica, cria os Institutos Federais de Educação, Ciência e Tecnologia, e dá outras providências. Diário Oficial [da] República Federativa do Brasil, Poder Legislativo, Brasília, DF, Seção 1, p. 1, 30 dez. 2008.

- Ministério da Educação. Secretaria de Educação Profissional e Tecnológica (Setec). Concepção e Diretrizes: Instituto Federal de Educação, Ciência e Tecnologia. Brasília, jun. 2008a. Disponível em: <http://www.poa.ifrs. edu.br/wpcontent/uploads/2010/03/concepcao_diretrizes.pdf $>$. Acesso em: set. 2013.

. Ministério da Educação. Plano de Desenvolvimento da Educação: razões, princípios e programas. 2007. Disponível em: <http://www. dominiopublico.gov.br/download/texto/me004370.pdf>. Acesso em: out. 2013. Acesso em: 9 dez. 2013. 
Decreto no 6.095, de 24 de abril de 2007. Estabelece diretrizes para o processo de integração de instituições federais de educação tecnológica, para fins de constituição dos Institutos Federais de Educação, Ciência e Tecnologia IFET, no âmbito da Rede Federal de Educação Tecnológica. Diário Oficial [da] República Federativa do Brasil, Poder Executivo, Brasília, DF, Seção 1 p. 6, 25 abr. 2007a.

Decreto $\mathrm{n}^{\circ} 2208$, de 17 de abril de 1997 . Regulamenta o $\int 2^{\circ}$ do art. 36 e os arts. 39 a 42 da Lei no 9.394, de 20 de dezembro de 1996, que estabelece as diretrizes e bases da educação nacional. Diário Oficial [da] República Federativa do Brasil, Poder Executivo, Brasília, DF, Seção 1, p. 7.760, 18 abr. 1997.

Lei no 9394, de 20 de dezembro de 1996. Estabelece as diretrizes e bases da educação nacional. Diário Oficial [da] República Federativa do Brasil, Poder Legislativo, Brasília, DF, Seção 1, p. 27.833, 23 dez. 1996.

BRASIL. Constituição da República Federativa do Brasil. Brasília, DF: Senado Federal, 1988.

CIAVATTA, M. Os Centros Federais de Educação Tecnológica e o ensino superior: duas lógicas em confronto. Educação \& Sociedade, Campinas, v. 27, n. 96, Especial, p. 911-934, out. 2006.

DINIZ-PEREIRA, J. E. Convergências e tensões nas pesquisas e nos debates sobre as licenciaturas no Brasil. In: DALBEN, Â. I. L. de F. et al. Convergências e tensões no campo da formação e do trabalho docente, Belo Horizonte: Autêntica, 2010, p.527-550.

Formação de professores: pesquisas, representações e poder. Belo Horizonte: Autêntica Editora, 2000.

As licenciaturas e as novas políticas educacionais para a formação docente. Educação e Sociedade, ano XX, n. 68, p. 109-125, dez. 1999.

DOURADO, L. F. A reforma do estado e as políticas de formação de professores nos anos 1990. In: DOURADO, L. F.; PARO, V. H. (Org.). Políticas Públicas \& Educação Básica. São Paulo: Xamã, 2001, p. 49-58. 
FREITAS. H. C. L. A (nova) política de formação de professores: a prioridade postergada. Educação \& Sociedade, Campinas, v. 28, n. 100, Especial, p.12031230, out. 2007.

FRIGOTTO, G.; CIAVATTA, M.; RAMOS, M. A gênese do Decreto n. 5.154/2004: um debate no contexto controverso da democracia restrita. In: FRIGOTTO, G.; CIAVATTA, M.; RAMOS, M. (Orgs.) Ensino médio integrado: concepção e contradições. São Paulo: Cortez, 2005, p. 21-56.

GATTI, B. A. Formação inicial de professores para a Educação Básica: pesquisas e políticas educacionais. Estudos em Avaliação Educacional, São Paulo, v. 25, n. 57 , p. 24-54, jan./abr.2014.

. Licenciaturas: crise sem mudança? In: DALBEN, A. I. L. de F. et al. Convergências e tensões no campo da formação e do trabalho docente, Belo Horizonte: Autêntica, 2010, p.485-508.

GatTi, B. A.; BARreto, E. S. de S.; ANDrÉ, M. E. D. de A. Políticas docentes no Brasil. Brasília: UNESCO, 2011.

IFSP - Instituto Federal de São Paulo. Relatório de Gestão do exercício de 2013. São Paulo, mar. 2014. Disponível em: <http://www.ifsp.edu.br/index. $\mathrm{php} /$ documentos-institucionais/relatorio-degestao.html?start=1>. Acesso em: 10 mai. 2014.

Plano de Desenvolvimento Institucional (PDI) 2009-2013. 2009. Disponível em: <http://www.ifsp.edu.br/index.php/documentosinstitucionais/ pdi.html>. Acesso em: 10 jul. 2014.

LIMA, M. F. B. A expansão das licenciaturas no Instituto Federal de Educação, Ciência e Tecnologia de São Paulo: percursos e características. 2015. 210p. Dissertação (Mestrado em Educação) - Programa de Pós- Graduação em Educação, Universidade de São Paulo, São Paulo, 2015.

MENEZES, L. C. Formar professores: tarefa da universidade. In: CATANI, D. B. et al. Universidade, escola e formação de professores. São Paulo: Editora Brasiliense, 1986, p.115-125. 
ORTIGARA, C. Reformas educacionais no período Lula (2003-2010): implementação nas instituições federais de ensino profissional. 2012. Tese (Doutorado em Educação) -Universidade Estadual de Campinas, Campinas/SP, 2012.

OTRANTO, C. R. Institutos Federais de Educação, Ciência e Tecnologia: novo lócus de formação docente no Brasil. In: SILVA JÚNIOR, João dos Reis; SOUSA, José Vieira; AZEVEDO, Mário Luiz Neves; CHAVEZ, Vera Lúcia Jacob (Orgs.). Educação Superior: internacionalização, mercantilização e repercussões em um campo de disputas. 1. ed. Belo Horizonte, MG: Fino Traço, 2015, p. 229-253.

Reforma da educação profissional no Brasil: marcos regulatórios e desafios. Revista Educação em Questão, Natal, v. 42, n. 28, p. 199-226, jan./ abr. 2012.

SAVIANI, D. Formação de Professores: aspectos históricos e teóricos do problema no contexto brasileiro. Revista Brasileira de Educação, v. 14, n. 40, p. 143-155, jan/abri., 2009.

O Plano de Desenvolvimento da Educação: análise do projeto do MEC.

Educação \& Sociedade, Campinas, v. 28, n. 100, Especial, p. 1231-1255, out. 2007.

- História da formação docente no Brasil: três momentos decisivos. Revista do Centro de Educação, vol. 30, n. 2, p. 11-26, jul./dez., 2005.

TANURI, L. M. História da formação de professores. Revista Brasileira de Educação, n. 14, p. 61-88, maio/jun./jul./ago., 2000.

TEIXEIRA, A. O problema de formação do magistério. Revista Brasileira de Estudos Pedagógicos. Brasília, v.46, n.104, p. 278-287, out./dez., 1966.

VEIGA, I. P. A. Docência como atividade profissional. In: VEIGA, I. P. A. Profissão docente: novos sentidos, novas perspectivas. Campinas, SP: Papirus, 2008, p. 13-21. 
VEIGA, I. P. A.; VIANA, C. M. Q. Q. Formação de Professores: um campo de possibilidades inovadoras. In: VEIGA, I. P. A.; SILVA, E. F. da (Orgs.). 3. ed. A escola mudou: que mude a formação de professores! Campinas, São Paulo: Papirus, 2011, p. 13-34.

MARIA FLÁVIA BATISTA LIMA é Mestra e Doutoranda em Educação na Faculdade de Educação da Universidade de São Paulo (FEUSP). É Pedagoga na Pró-reitoria de Graduação da Universidade Federal do ABC (UFABC). E-mail: flavia.lima02@usp.br

GLADYS BEATRIZ BARREYRO é Doutora em Educação (USP). Professora da Universidade de São Paulo, na EACH e no Programa de Pós-Graduação em Educação, na FEUSP. Desenvolveu pesquisa pós-doutoral no Center for International Higher Education, no Boston College, EUA. Foi professora visitante no Centre for Globalisation, Education and Social Futures na University of Bristol, Reino Unido. É membro da rede Universitas/BR do GT11- Educação superior vinculado à ANPED e do Grupo de trabalho Universidad y políticas de educación superior da Clacso. É coordenadora do Grupo de Estudos em Políticas Públicas e História da Avaliação da Educação Superior (GEPPHAES/ USP).E-mail: gladysb@usp.br

Recebido em fevereiro de 2018 Aprovado em junbo de 2018 